امكانية استعمال مستخلص كالس نبات عرق السوس

Glycyrrhiza glabra L.

$$
\text { في المزارع النسيجية }
$$

\title{
The possibility of using Glycyrrhiza glabra L. Callus extracts as an alternative to plant growth regulators in plant tissue culture experiments
}

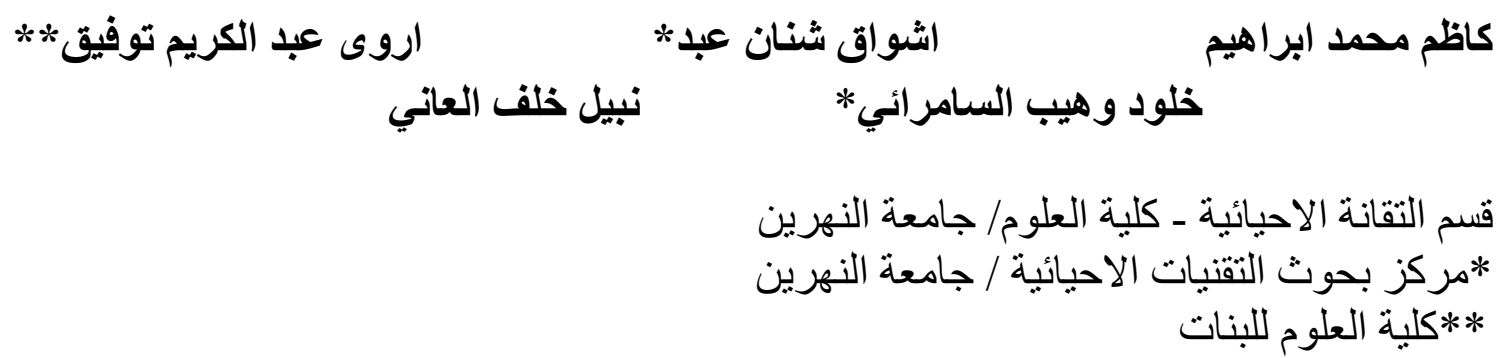

المستخلص

يعد نبـات عرق السـوس مـن النباتـات المهــمة على المستوى الطبـي والاقتصـــادي ، كونـهـ غنيـا بالمركبـات

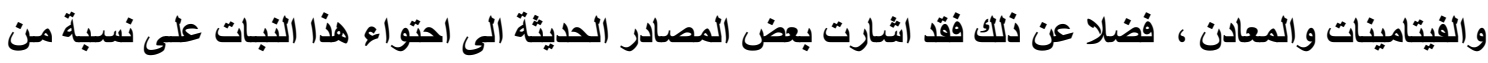
منظمات النمو النباتية ، لذا تم وضعه قيد الاراسـة المختبريـة لمعرفة مدى امكانية استعمال مستخلصـات الكالس

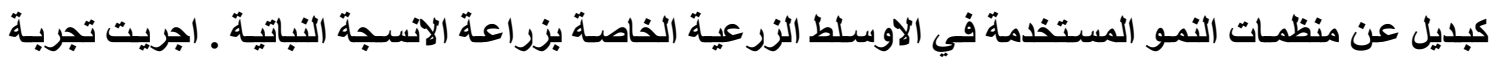

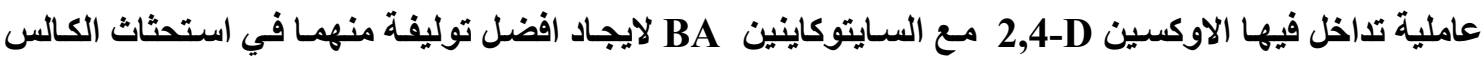
على الاجزاء النباتية لعرق السوس ، وقد وجد بان التوليفة (2) ملفم/لتر من 2,4-D مع (2.5) ملفم/لترمن BA مانسين افضلها من حيث كمية الكالس المنتجة ، لذا اعتمدت هذه التوليفة في انتاج الكالس في التجارب اللاحقة. اجري

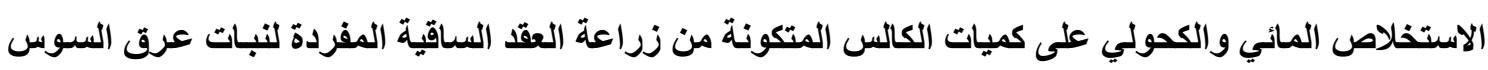
على الوسط الزرعي MS لغرض استخلام تراكيز مختلفة من هذين المستخلصين(0، 2، 4، 6، 8 أو 10) مل/لتر كبايل لمنظمسات النمو، في تاثير هـا في نمو وتطور انسجة واعضـاء عدد من النباتـات كفول الصويا و البطاطا والحنطة خارج الجسم الحي ـ اظهرت النتائج التاثير الايجابي للمستخلص المـائي على نشوء الافرع من العقد المفردة للبطاطا، لا سيما عند التراكيز العالية منه ـ فيما اعطى كلا المستخلصين زيادة معنويـة واضحة في وزن الكالس لنبات فول الصويا، اما التاثير على النمو الخضري و الجذري للحنطة ، فقد وجد ان تاثير المستخلص المـائي كان ذو فعاليـة اكثر من المستخلص الكحولي في زيـادة اطوال المجموعين الخضري والجذري لبادرات الحنطة.

\section{Abstract}

Liquorices' plant is considered one of the important medicinal and economical plants. It is rich with many compounds, minerals, vitamins, and even plant hormones. This research is aimed to study the possibility of using callus tissue extracts as an alternative to plant growth regulators added to the culture media. A 
factorial experiment was implemented to find out the appropriate combination between 2, 4-D and BA for callus induction on Liquorice node explants. It was found that a combination of $2 \mathrm{mg} / \mathrm{l} \mathrm{2,} \mathrm{4-D} \mathrm{with} 2.5 \mathrm{mg} / \mathrm{l} \mathrm{BA}$ is the best one for callus induction and maintenance using MS medium. Water and alcoholic extracts were prepared from callus tissue at concentrations $(0,2,4,6,8$ or 10$) \mathrm{ml} / \mathrm{l}$ then added to culture medium as an alternative to plant growth regulators. The effect of these concentrations on growth and development of tissues and organs for some plants was studied using soya bean, potato and wheat plants for this purpose. Results showed that water extract induced shoot proliferation from potato single nodes. Both types of extracts increased soya bean callus fresh weight significantly. It was found also that water extract was more effective than alcoholic one in increasing vegetative and root parts in germinating wheat seeds.

\begin{tabular}{|c|c|}
\hline & 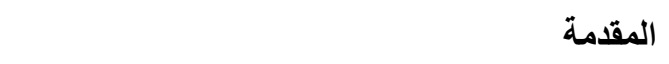 \\
\hline ، ويكثر خضريا بزرع قطع فتية من مداداته ، كما & نبــات عــرق الســوس مــن نباتــات العائلــة البقوليــة \\
\hline يمكن اكثاره بالبذور ـ و اجزاء هذا النبات المستعملة & (Fabaceae) و واســمه العلمـي (Fـe \\
\hline طبيا هي الجذور و الددادات [2] ـ ويحتوي عرق & glabra ، امــــا اســـمه الانكليــزي فهـــو \\
\hline السوس على الكثير من المركبات الكيميائية النباتية & 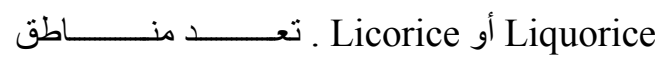 \\
\hline والتي يمكن تصنيفها الى (Phytochemicals) & البحـر الابيض المتوســـو اسـيا الصـغرى وتركسـتان \\
\hline ثمانية مجاميع رئيسية هي : & شـرقا الـى اسـبانيا غربـا المـواطن الاصـلية للنبـات ، \\
\hline 1- مركبـات (Terpenoids) : و هي مركبات دهنية & ويعد هذا النبات في العراق من الادغال التي تنمو في \\
\hline تضـم glycyrrhetol $\beta$-amyrin glycyrrhizin & الحقــــول و البســــاتين وضــــفاف الانهــــار وبــين \\
\hline و liquiritic و licoric acid g glabrolide & المزروعـات، ويكثر نواجـه في الموصـل و الســـل \\
\hline . acid & الرسـوبي الثــرقي و الاوســ، ومنطقــة المسـتنقعات \\
\hline 2- مركبــات (Isoflavones و Flavonoids): & 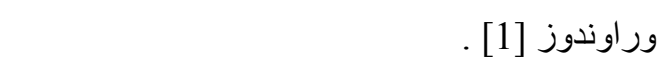 \\
\hline و هي مركبات فينولية تضم & وتوجد عدة اصناف من هذا النبات واهمها تجاريا ، \\
\hline labrol glabrin و و glabrone و و lycyrol glabrel & ثلاث انواع هي عرق السوس الاسباني (. Liq \\
\hline 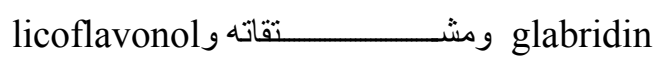 & (Spanish) و الروسي (Russian Liq) و الفارسي \\
\hline 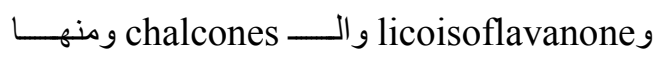 & (Persian Liq.) ، ويوجد النوع الاخير في كل من (P) \\
\hline licuraside,$\quad$ isoliquiritigenin & العراق وايران ، والذي يتميز بأزهاره ذات اللون \\
\hline و licochalcones A, B. & البنفسجي ، و هو من الاعشاب المعمرة يصل ارتفاعه \\
\hline 3- مركبـات (Coumarins): وهي مـن المركبـات & الى حوالي (1.5) م ـ ويتكون مجموعه الجذري من \\
\hline الفينوليــة ايضــــــــ glcyrine و و و و & جذور رئيسية طويلة ورايزومات او مدادات رفيعة ، \\
\hline umbellifero & $\|=$ \\
\hline
\end{tabular}


الهرمونــــات الجنســـية فــــي الانســــان ، مثــلـل [6,5] لذا فهو يعمل على Phytoesterogen تنظيم مستوى الهرمونـات في جسم الانسـان لاسيما

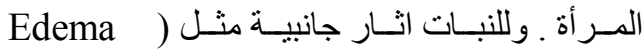
( ) كمـا يزيـد من (Hypokalemia) ، (formation

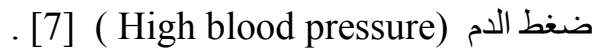
2- الاسـتعمالات الغذائيـة : عنصـر بضـــف نكهـة

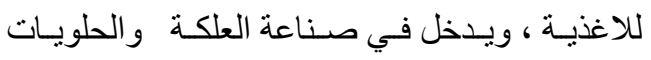
و السكاير و انواع التبوغ ولزيـادة الرغوة في صناعة

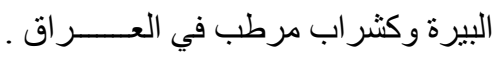
3- الاستعمالات الزر اعية : يؤمل كثير ا في ان يكون

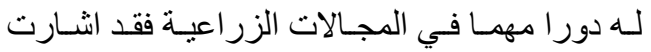

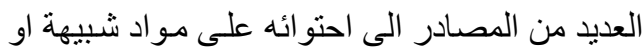

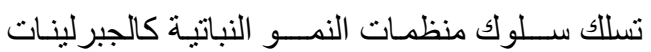

و لاهمية هذا النبات فقد اهتمت العديد من الدراسـات

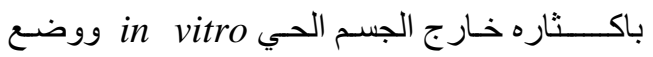
بعض الحلول المناسبة للمشكلات التي تواجها هذا الاكثتـــــ ، [11,10 كما درس العديد من الباحثين زر اعة عر ق السوس نسيجيا لغرض تكوين الكالس لزيــادة كميـة و اســتخلاص المركبـات الفعالــة منــهـ [16,15,14,13,12] ـ لـذا هـدفت الدر اســة الحاليـة الـى امكانيـة اضـافة مستخلصـات الكـالس المائيـة و الكحوليــة الــى الهـز ار ع النسـيجية فــي محاولـــة لاستعمال هذه المستخلصات بديلاً عن منظـات النمو النباتيـة الضـرورية لنــو الانسـة النباتيـة المزوعـة

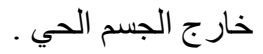

دقيقة واحدة ، ثم عقمت سطحيا بمحلول هاييوكلورات

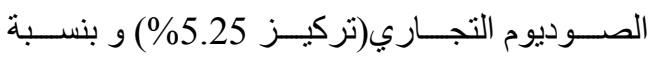

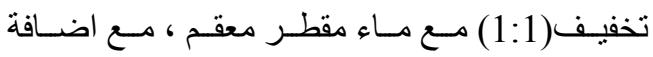

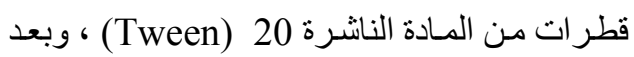

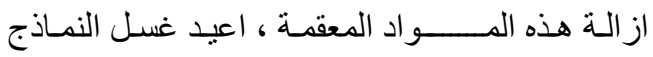
بالكحول الاثيلي 70\% لمدة نصف دقيقة ، ثم غسلت
4- B2 ، B1 الفيتامينـات (Vitamins) : وتضــ

‘ Folic acid ، Biotin` E ، C ، B6 ، B3 . Pantothenic acid 5- العناصر المعدنية (Minerals) : وتثـمل المنيوم

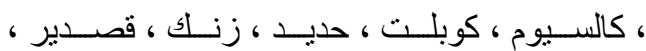
مغنيسيوم ، منغنيز ، فسفور ، سليكون .

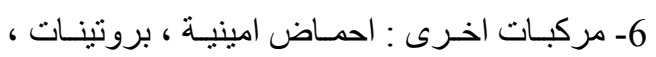
لكنـين ، صــبغات صــفر اء ، ســكريات كـالكلوكوز و السكروز و الفركتوز و المانيتول و المالتوز.

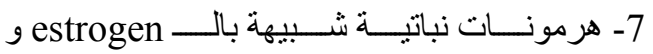

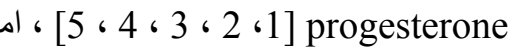
اسـتعمالاته فـيمكن تصـنـيفها الـى طبيــة و غذائيـة

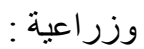

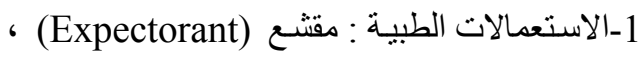
ملـين (Laxative) ، ولعــلاج القرحسـة المعديـة Chronic و التهابـات المعـدة (Pepticulcer) gastritis القصبات الهو ائية (Bronchialcatarrh) و امر اض

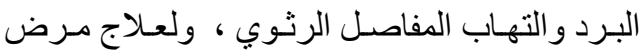

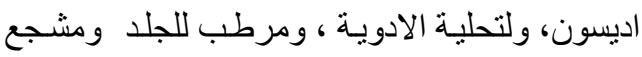

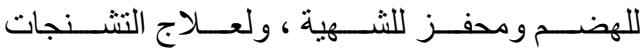
، (Herpes) (Antispasmodic)

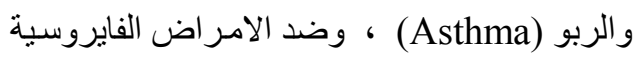

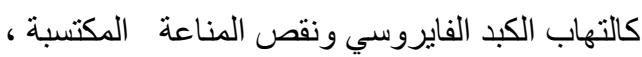

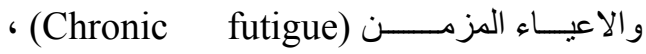
و 23,4,2,1] [Hypoglycemia) ـ و لاحتو ائسه علىى هرمونــات نباتيـة مشـابهة لعمل المواد وطر ائق العمل - تعقيم الاجز اء النباتيـة لعـرق السـوس : قطعت الافرع الساقية الغضة للحصول على العقد كمصادر للاجز اء النباتيـة المزروعـة (Explants) ، و غسلت

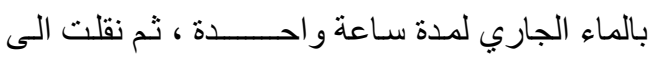

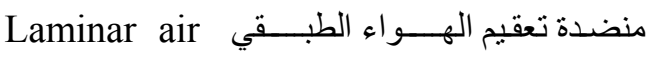
flow hood ، و غسلت بالكحول الاثيلي 70\% لمدة 
رشـح ونبـذ بجهـاز الطـرد المركزي عندـ 2000 دورة/ دقيقة ولمدة 10 دقائق ، و ركز الر ائق الى النصـف عنــد درجـة حـرارة 25 -28م ، وعــقم

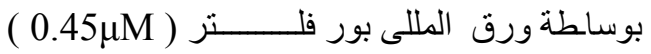

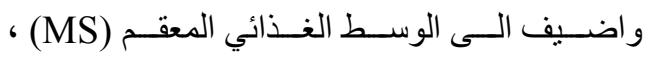

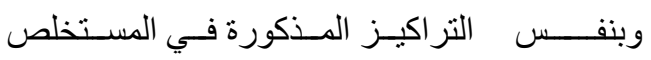
المائـــي .

دراسة تأثير المستخلصات في بعض معايير النمو : 1- فول الصويا : زرع كالس فول الصويا والذي انـــتج حســــب ما ورد فـــي [22] على الوسط الزرعي (MS) ، و الحاوي على التراكيز الدذكورة سابقا للمستخلصات المائية والكحولية لكالس عرق السوس فقد زرع وزن كالس بمعدل (150) ملغم لكل انبوبة زرعية وبواقع (10) مكررات وحضنت

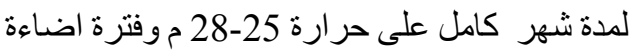
16ساعة/يوم وشدة اضاءة 3000 لوكس ، وبعدها تم حساب الفرق في الوزن الطري للكالس ليكون دالة على نأثير كل من المستخلصين المائي والكحولي على هذا النمو بعد مقارنته بالاوساط التي لا تحتوي على مستخلص عرق السوس . 2- البطاطا : قطعت افرع البطاطا المزروعة نسيجيا في المختبر الى عدد من القطع كل قطعة تحتوي على عقدة مفـردة واحـدة (Single node) بعـد ان تـم اكثار هـا كما ورد في [22] وزرعت على الاوسـاط

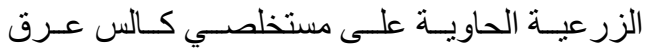
السوس وبو اقع (10) مكررات ، حضنت تحت نفس ظروف الحضن المذكورة سـابقا ، ولمدة شهر ، ثم

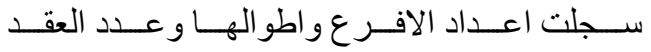

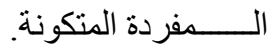
3- الحنطــة : زرعـت بـذور الحنطـة (صـنف ابـو غريب3) في اطباق بتري معقـمة حاوية على الوسط

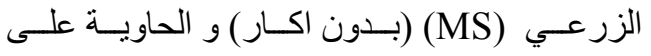

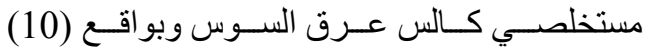
مكررات ، وحضنت ثـلاث ايام في الظلام ، ثم نقلت
بالمــاء المقطــر المعقم ثـلاثت مـر ات ، وقطعــت الـى طول (1) سم وزرعت على الاوسـاط الزرعية ، في قناني زجاجية (vials) ذ ذات ابعاد (2x 8) سم .

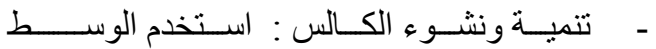
لغرض (MS) Murashige and Skoog 1962 تتمية الكالس من الاجز اء النباتيـة المزروعة (العقد) وباستخدام عدد من المعاملات الهرمونيـة والمتضمنة هرمـوني النمـو (BAP (2,4-D) بصـورتيهما المفردة والمتـاخلـة مـع بعضـهم البعض ، وحسب

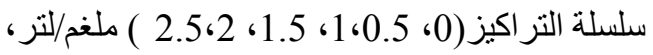
وبو اقــــع (10) مكررات لكل تركيز . حضنت الانابيب عند درجة حرارة25 -28م ، وفترة اضلاءة اضـاءة 16 سـاعة/يوم وشدة اضـاءة مقدار ها 3000 لوكس ـ وقد استخدم الوسط المذكور وفقا لمـا اشـار اليهـ المصدر [11] في اكثار نبـات عــــرق السوس نسيجيا باستخدام الوسط الزرعي (MS) . - مستخلص كالس عرق السوس : بعد (6) اسابيع مـن زر اعـة العقد ونشـــــــوء الكـالس ، تـم حصــاد الكالس المتكون و استخلاصه مائيا وكحوليا : أـ الاستخلاص المائي : استخلص الكالس مائيا كما ورد في[18] ، بأخذ (1) غم من الكالس ونقعه في (10) مل من الماء المقطر المعقم ، ثم سحق في

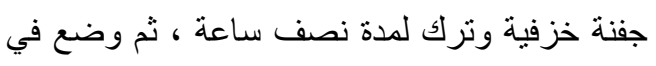
حمام مائي و على درجة الغليان لمدة ساعة ، بعدها تم ترشيح المستخلص ونبذ مركزيا على 2000 دورة/دقيقة ولمدة 10 دقائق ، ثم بخر الراشح وركز الى نصفه على درجة حرارة 45 م . عقم بورق التعقيم مللي بور فلتر( الوسط الزرعي (MS) المعقم وبتر اكيز (0 ، 2، 4

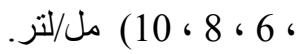

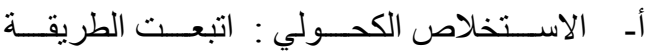
المذكورة من قبل [19] ، اذ تم وزن غرام واحد من الكالس ونقع بالكحول الاثيلي $70 \%$ مل ولمدة يوم كامل ومن ثم سحق بالهاون الخزفي ، بل بل 
المجمـوع الجـذري لبـادر ات نبـات الحنطــة (طـول الجذور) ، لمعرفـة مدى تأنت

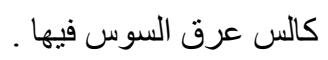

لفترة اضـاءة مقدار ها 16 سـاعة/يوم ، عند حـر ارة

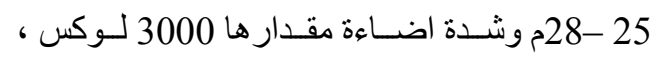

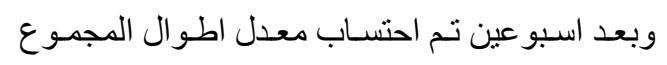

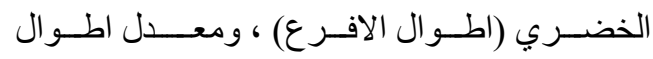

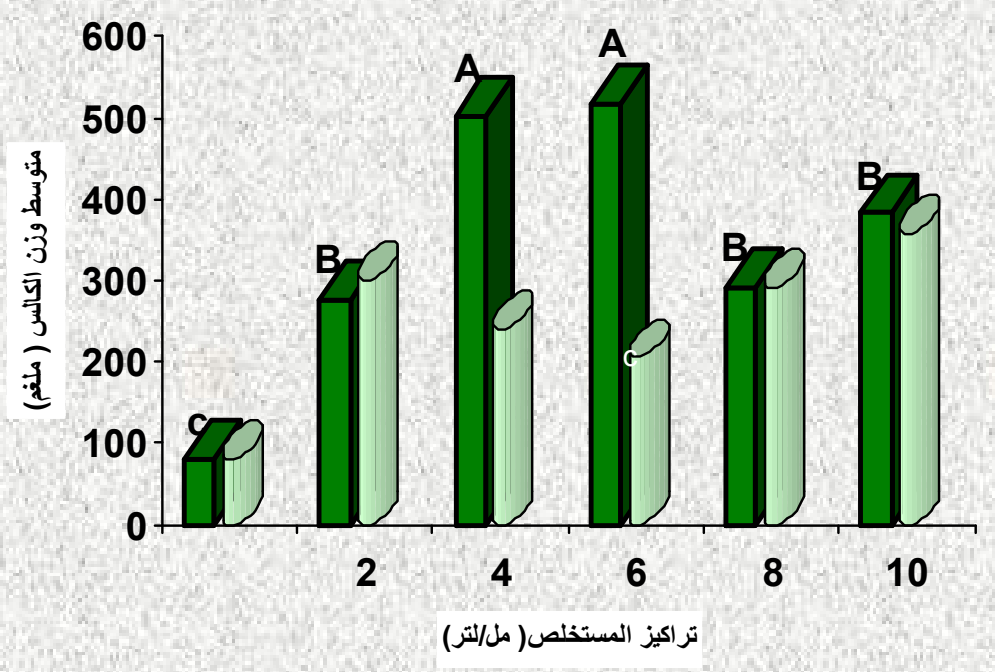

شكل (1): تأثير المستخلص المائي والكحولي لكالس عرق السوس في متوسط الوزن الطري (ملفز)

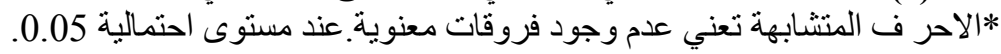

الــداكن بعـــ الاسـبوع ع الســادس مـن الزر اعـة) ) وبالاعتماد على هذه النتيجة تم انتخاب هذه المعاملـة

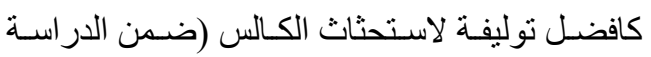

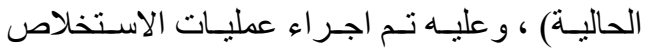

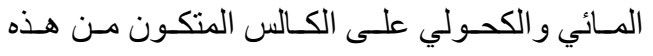
المعاملة .

السيطرة والتي بلغ فيها وزن الكالس (80) ملغم فقط و هو الوزن الابتدائي للكالس . اما تأثير المستخلص الكحولي فقد اظهر ايضـا فرقا معنويا في زيادة نمو خلايا الكالس مقارنة مع معاملة السيطرة و عند جميع تر اكيز المستخلص المدروسـة

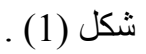

2- تأثنير المستخلصات في عدد الافرع واطوالها وعدد العقد لنبات البطاطا أثر المستخلص المائي لكالس عرق السوس معنويا في زيادة عدد افرع نبات
نشـوء الكـالس : اتبعـت طريقـة [23] في اسـتحثاث

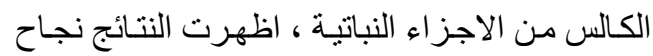
توليفة منظمـات النمو (2,4-D BA+2.0 ملغم/لتر في استحثاث الكالس على الاجز اء النباتيـة المزرو عـة على الوسط الغذائي بعد (6) اسـابيع من الزراعـة (مـع ملاحظة تغير لون الكالس الى اللون النتائج تأثثير المستخلصات على بعض معايير النمو : 1- تأثثر المستخلصات في نمو كالس فول الصويا :

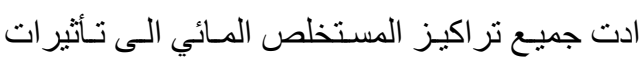

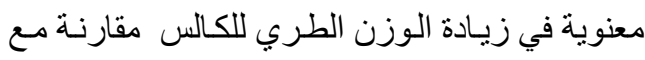
معاملة السيطرة، وكانت اعلاها عند التركيزين (4 و معريك 6) مل/لتر و اللتين اظهرتـا ارتفاعـا كبير ا في نمو خلايـا الكالس محققة فرقا معنويـا بينها وبين سـائر معساملات او تر اكيز المستخلص المـائي ، اذ بلغتـا (502 و518 ) ملغم على التو الي مقارنـة مـع معاملـة 
وانخفضت عند التركيز(6) مل/لترللمستخلص ذاته ، في حين انخفضت أطوال الافرع معنويا عند جميع تراكيز المستخلص الكحولي مقارنة مع معاملة

السيطرة شكل (3 ) - (3)
البطاطا عند التركيز (6) مل/لتر، في حين لم يؤثر المستخلص الكحولي في ذلك ولكافة التراكيز المدروسة شكل(2) ـ اما أطوال الافرع فقد ازدادت معنويا عند التركيز(10) مل/لتر للمستخلص المائي

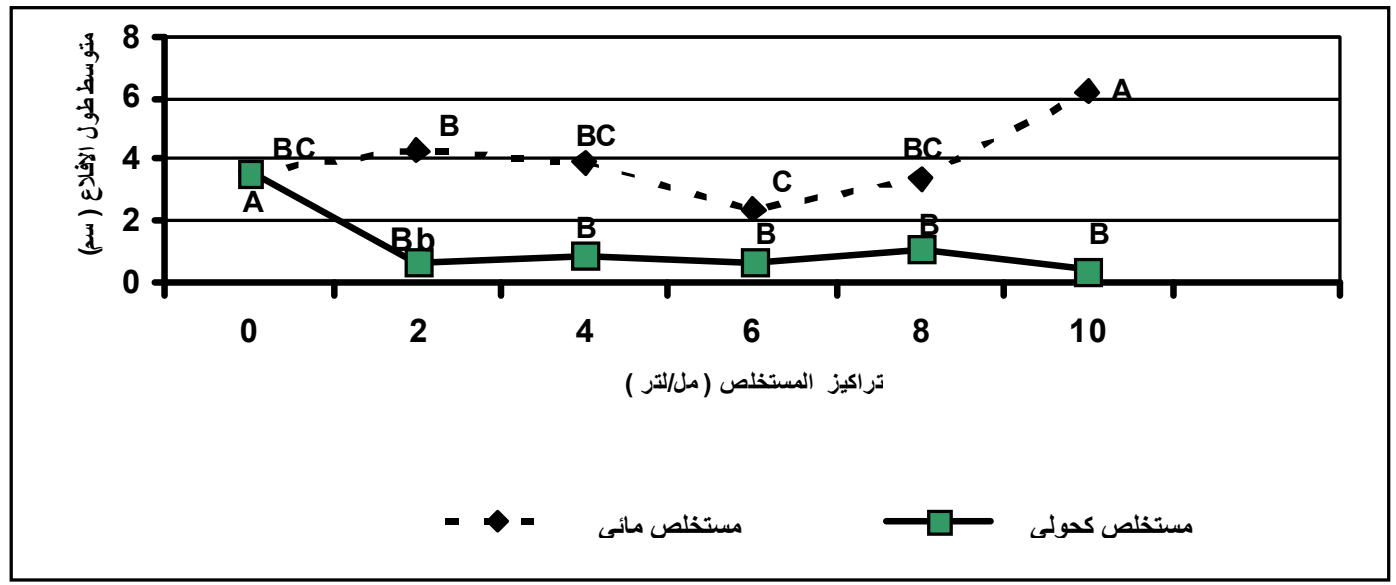

شكل(2): تأثير المستخلص المـائي والكحولي لكالس عرق السوس في متوسط عدد الافرع المتكونـة على العقد المفردة

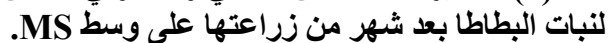

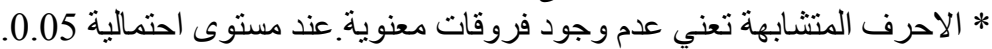

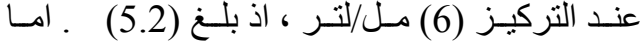
المستخلص الكحولي فقد أثر معنويـا بتقليل متوسط عـدد العقـــ المفـردة المتكونــة عنــد جميـع تراكيـز المستخلص قيد الدر اسـة مقارنـة مـع معاملـة السيطرة

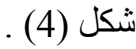

و عنــد ملاحظـة النتـائج الخاصـة بتـأثير المسـتخلص المائي على متوسط عدد العقد المفردة المتكونـة وجد بأن التركيز(10) مل/لتر هي المعاملة الوحيدة التي أظهرت زيادة معنوية في متوسط عدد العقد المفردة المنكونة والبالغة (12.5) مقارنة مع معاملة السيطرة و البالغـة (7.6) ، في حين انخفض المنوسط معنويـا

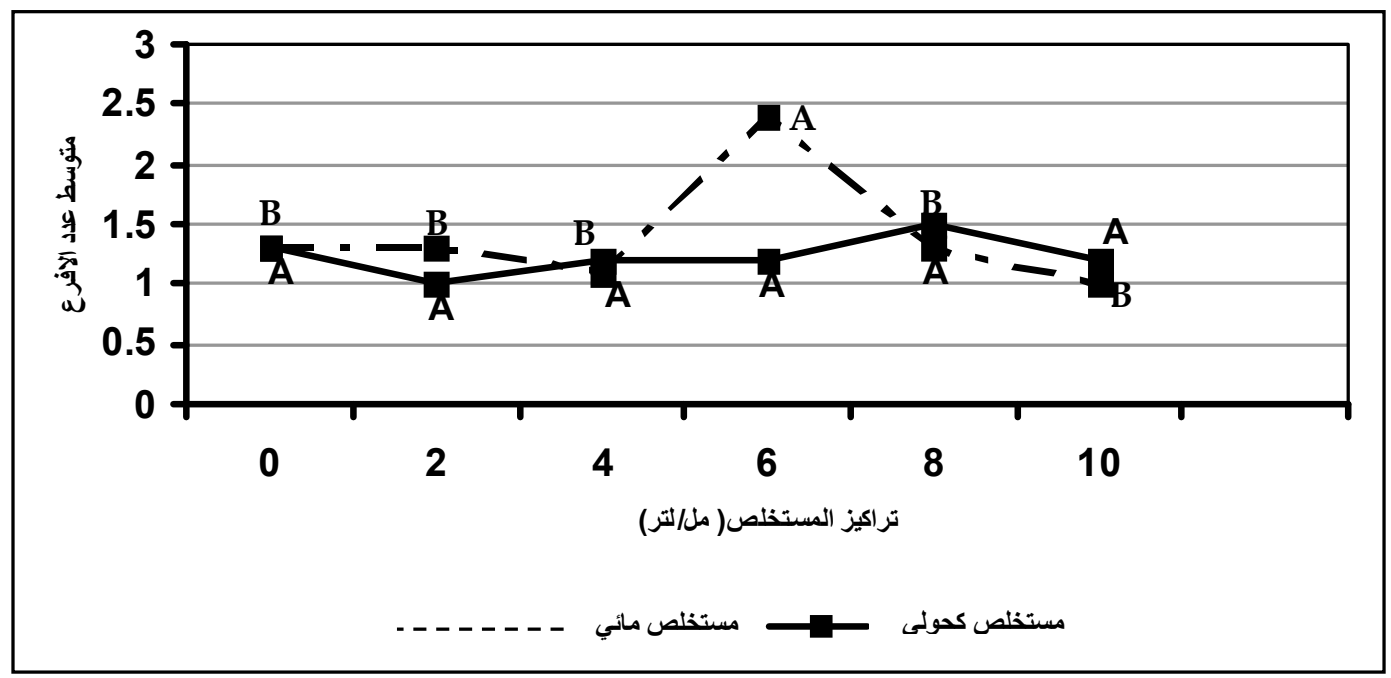

شكل(3): تأثير المستخلص المائي والكحولي لكالس عرق السوس على طول الافرع(سم) المتكونة على العقد المفردة

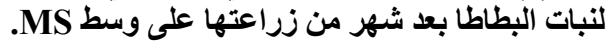
* الاحرف المنتابهة تعني عدم وجود فروقات زيطات معنوية. عند مستوى احتمالية 0.05. 


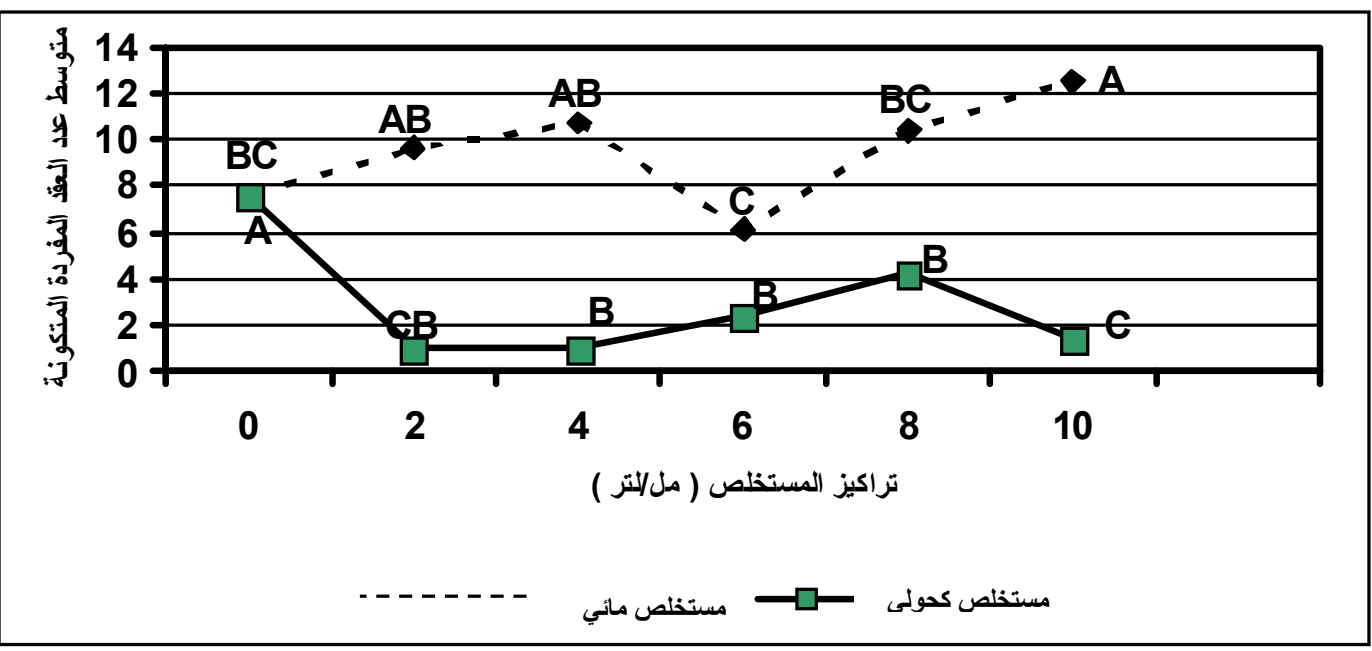

شكل(4): تأثير المستخلص المـائي والكحولي لكالس عرق السـوس في متوسط عدد العقد المفردة المتكونـة لنبـات

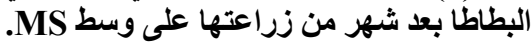

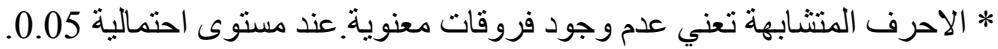

الخضــري و(7.5، 6.1 ، 5.1) ســـ علــى التـــو الي للمجمـوع الجـذري ، مقارنــة مـع معاملـة السـيطرة والبالغة (13) سم للخضري و (3.4) سم للجذري . في حين لـم يظهر المستخلص الكحـــي اي تـأثير معنـوي على نمـو كل مـن المجمـوعين الخضـري

$$
\text { و الجذري شكل(5 ،6) . }
$$

3- تأثير المستخلصات في نمو بادرات نبات الحنطة: اظهرت النتائج زيادة طول المجموعين(الخضري

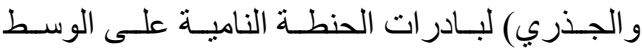

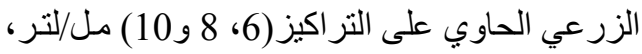
من المستخلص المائي ، وكانت هذه الزيـادة معنويـة

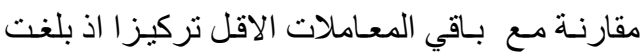
(17.6، 14.5و17.8) سـم على التـو الي للمجمـوع ع
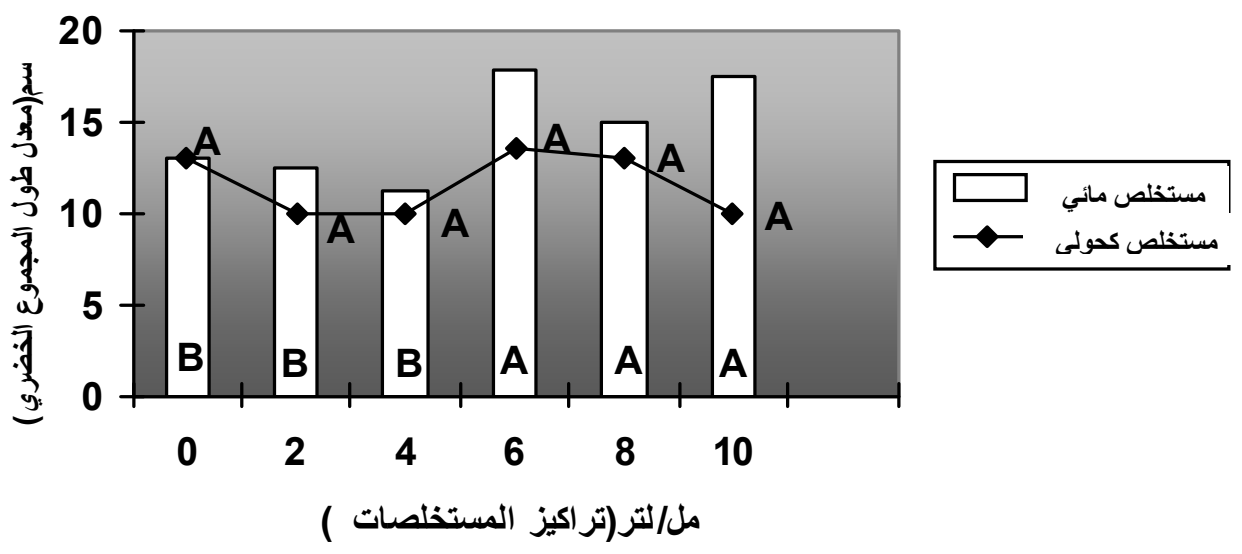

شكل(5): تأثير المستخلص المائي والكحولي لكالس عرق السوس في متوسط طول المجموع الخضري(سم) لبادرات

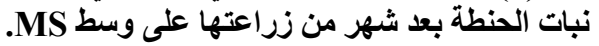




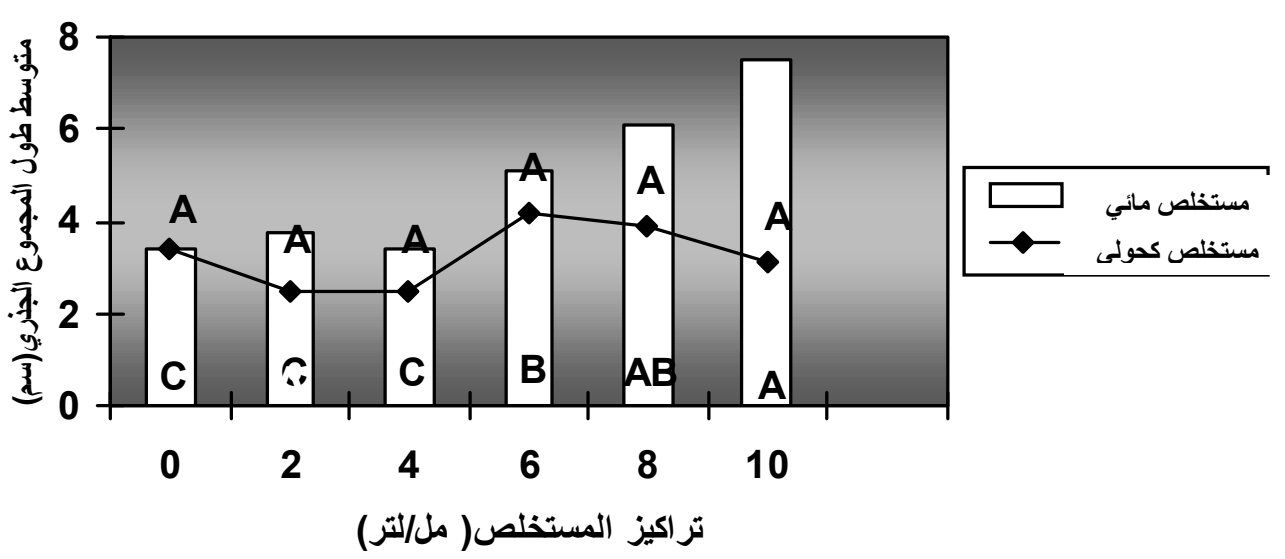

شكل(6): تأثير المستخلص المائي والكحولي لكالس عرق السوس في متوسط طول المجموع الجذري(سم) لبادرات

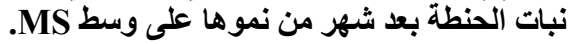
* الاحرف المتشابهة تعني عدم وجود فرو فيط وقات معنوية.تحت احتمالية 0.05.

المناقثة

الحمضيات واعطاء التركيز (6) مل مستخلص/لتر نتائج منوافقة مع التركيز (2) ملغم/لتر GA3 في تأثير ها الفسلجي على نمو الزروعات خارج الجسم الحي ـ امازيادة عدد افرع نبات البطاطا عند التركيز (6) مل/لتر و انخفاض طول هذه الافرع وكذللك عدد العقد المفردة المتكونة فيها عند النركيز ذاته ، فهذا قد ولد يعود الى ان مركبات الكومارين التي يحتويها مستخلص عرق السوس [4] شجعت على زيادة عدد افرع النبات على حساب طول هذه الافرع وعدد العقد المفردة المتكونة فيها ، وعليه فمن الممكن النصح باستخدام التركيز(6) مل/لتر اذا ما اريد زيادة عدد الافرع لزروعات البطاطا النامية خارج الجسم الحي ـ وينصح ايضا بأستخدام المستخلص المائي فقط ( دون الكحولي ) في ابحاث تنمية نباتات الحنطة لكفائته في زيادة نمو كل من المجموعين الخضـــــري والجذري ، لاسيما التر اكيز العالية منه (6 ، 8 و 10) مل//لتر ـ ويستنتج من النتائج السابقة الى امكانية استخدام مستخلصات كالس نبات عرق السوس بديلا عن منظمات النمو في الزراعة خارج الجسم الحي وبنفس الكفاءة وكذلك في نمو بادرات
يلاحظ من النتائج المستحصلة من هذا البحث تفوق المستخلص المائي على الكحولي في تأثيره الايجابي لئي ، لاسيما التركيز (6) مل/لتر ، في جميع الصفات

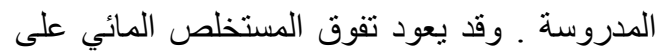

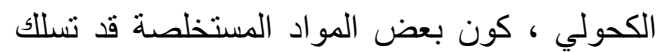

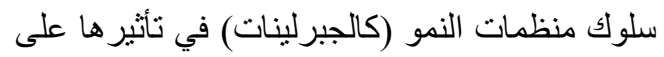
النمو وفي ميلها العالي للذوبان في الماء ، فقد اشنارت [9] الى ان رش المستخلص المائي لعرق السوس بتركيز (2.5) غم مسحوق/لتز على نبات الفريزيا Freesia hybrida L. أعطى افضل المؤشرات ذات التأثثر المعنوي على النمو و الازهار والعمر المزهري لنبات الفريزيا ، وعزت ذللك الى سلوك المستخلص سلوك الجبرلين في تأثيره الفسلجي

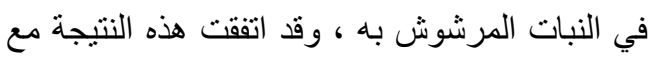
ما ذكره [20] بان مستخلص عرق السوس يسلك سلوك الجبرلين في تأثيره الفسلجي بتر اكيز(2.5-3 بـان

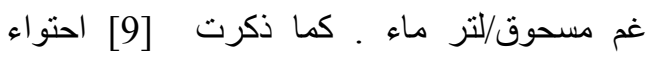
المستخلص المائي لعرق السوس على منظمات النمو (الجبرلينات) او مواد شبيهة بها بسبب التأثير المعنوي لهذا المستخلص في زيادة نمو وتفرع 


$$
\begin{aligned}
& \text { وراثيا (Transformed cells) لنبات عرق } \\
& \text { السوس بزيد بمقدار الضعف عنه في الخلايا غير } \\
& \text { المهندسة ور اثثا . }
\end{aligned}
$$

6- Bonham, M., Arnold, H., Montgomery, B. and Nelson, P.S. (2002). Molecular effects of the herbal compound PCSPES. Identification of activity pathways in prostate carcinoma. Cancer Research, 62: 3920-3924.

7- Rudolf fritz Weiss, M.D. and Volker fintelmann, M.D. (2000). Herbal Medicine. $2^{\text {nd }}$ ed., revised and expanded. Thieme Stuttgart. New York. Pp: 66-68. 8- الثمـــري، ماجدة عبد الكاظم سالم (2003). تأثير مستخلصي بذور وكوالح الـــذرة الصفراء وجذور

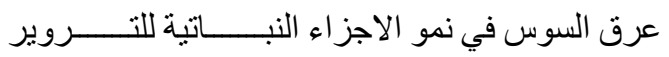
Poncirus trifoliate L. Raf $\mathrm{x}$ Citrus sinensis L. Osbeck الحي. رسالة ماجستير. كلية الزراعة / جامعة بغداد.

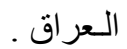

9- الربيعي، نوال محمود علوان منصور(2003). تأثثر الرش بالمحلول المغذي النهرين ومستخلص عرق

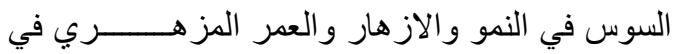

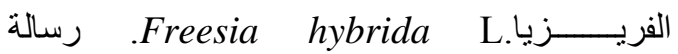

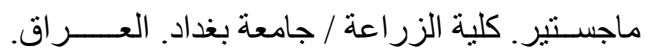

10- Masoodi, N. A. and Srivastava, L. J. (1994). Studies on the effect of growth regulators on initiation of rooting in cuttings of Glycyrrhiza glabra Linn. Indian Journal of Plant Physiol. 37(1): 28-29.

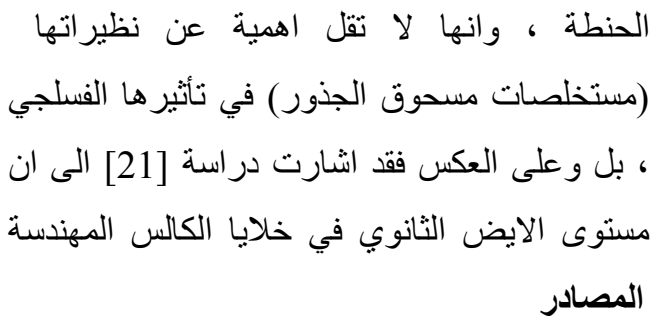

1- مجيد، سامي هاشم و محمود، مهند جميل (1988). النباتات و الاعثاب العر اقية بين الطب الثعبي و البحث العلمي. الطبعة الاولى. مجلس البحث العلمي. مركز بحوث علوم الحياة، قسم العقاقير وتقييم الادوية.

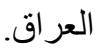

2- Evans, W.C. (1999). Trease and Evans“ Pharmacognosy. 14 ed., Saunders Company Ltd.

3- Fuhrman, B., Buch, S., Vaya, J., Belinky, P.A., Coleman, R., Hayek, T. and Aviram, M. (1997). Licorice extract and its major polyphenol glabridin protect low-density lipoprotein against lipid peroxidation:In vitro and Ex vivo studies in humans and in atherosclerotic apolipoprotei E-deficient mice. Americ. J. of Clinical Nutrition, 66: 267-275.

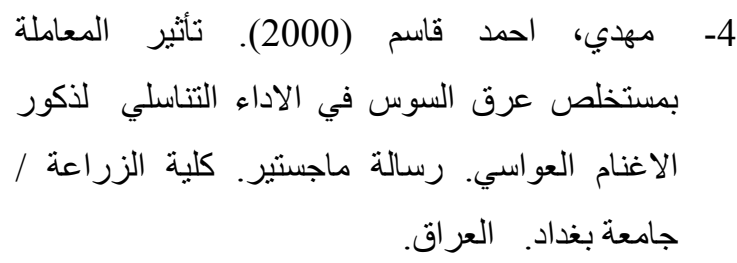

5- Sovak, M., Seligson, A.L., Konas, M., Hajduch, M., Dolezal, M., Machala, M., and Nagourney, R. (2002). Herbal composition PC-SPES for management of prostate cancer: Identification of active principles. J. of the National Cancer Institute, 94 (17): 1275-1280. 
bioassays with tobacco tissue culture. Physiol. Plant., 15: 473-497.

18- Yashimichi, S., Hisamitsu, N. and Youki, O. (1986). Anti mutagencity of extract from crude drugs in Chiness medicine. Mutation Research, 174 :1-4.

19- Swamy, S.M. (2000). Cytogenetic and immunopotential effects of Ethanolic extract of Nigella sativa seeds. J. Ethanopharma, 70 (1) : 1-7.

20- المرسومي، حمود غربي خليفة (1999). دراسة العوامل المؤثرة على صفــــات النمو الخضري وحاصل البذور في البصل Allium cepa. اطروحة دكتور اه. كلية الزر اعة/ جامعة بغداد. العراق.

21- Kovalenko, P.G., Antonjuk, V.P. and Maliuta, S.S. (2002). Secondary Metabolites production from transformed cells of Glycyrrhiza glabra and Potentilla alba as producents of Radioprotective compounds.Ukrainica Bioorganica Acta, $1(1): 21-32$.

22- العبيدي ، هاثم كاظم (2005). استحداث التغايرات الوراثية لتحمل الملوحة خارج الجسم الحي في

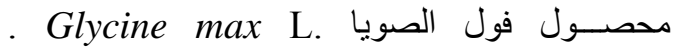
اطــروحة دكتـوراه. كلية العلوم/ الجامعة

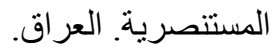

23- Ankica, K., Sesek, S., Maatencic, D. and Popovic, M. (1998). Utilization of callus culture as a preselection test for the salt tolerance of wheat (triticum aestivum L.) Proceeding of Balkan Symposium on field crops. Yogoslavia.
11- Thengane, S.R., Kulkarni, D.K. and Krishnamurthy, K.V. (1998). Micropropagation of Licorice Glycyrrhiza glabra L. through shoot tip and nodal cultures. Society for in vitro Biology.

12- Arias, C. C.and Scragg, A. H. (1993). The effect of cultural conditions on the accumulation of formononetin by suspension cultures of Glycyrrhiza glabra. Plant Cell Tissue and Organ Culture 34(1): 63-70.

13- Kakutani, K., K. Ozaki, K.,Watanabe, H. and Tomoda, K. (1997). Preparation of licorice seedling by node culture, and glycyrrhizin production by several nutricultures using the seedling. Natural Medicines, 51(5): 447-451.

14- Li, W. and Asada, Y. (1998). Antimicrobial flavonoids from Glycyrrhiza glabra hairy root cultures. Planta Medica 64(8): 746-747.

15- Asada, Y., Li, W. and Yoshikawa, T. (1998). Isoprenylated flavonoids from hairy root cultures of Glycyrrhiza glabra. Phytochemistry, Oxford 47(3): 389-392.

16- Asada, Y and Li, W. (1999). The first prenylated biaurone, licoagrone from hairy root cultures of Glycyrrhiza glabra. Phytochemistry, Oxford. March 50(6): 1015-1019.

17- Murashige, T. and Skoog, T. (1962). A revised medium for rapid growth and 